\title{
Preparation of Lithium Niobate Nanoparticles by High Energy Ball Milling and their Characterization
}

\author{
Sujan Kar ${ }^{1}$, Shweta Logad ${ }^{2}$, Om P Choudhary ${ }^{3}$, Chiranjit Debnath ${ }^{1}$, Sunil Verma $^{1}$, Kunwar S Bartwal $^{1, *}$ \\ ${ }^{1}$ Laser Materials Development \& Devices Division, RRCAT, Indore- 452013, India \\ ${ }^{2}$ Department of Physics, Vikram University, Ujjain, India \\ ${ }^{3}$ Department of Applied Physics, GSITS, Indore- 452003, India \\ *Corresponding Author: bartwalks@yahoo.co.in
}

Copyright $@ 2013$ Horizon Research Publishing All rights reserved.

\begin{abstract}
We present investigations on the preparation of lithium niobate, $\mathrm{LiNbO} 3$ nanoparticles using high energy ball-milling. Stoichiometric composition of $\mathrm{LiNbO} 3$ powder was prepared by solid-state reaction method and used for ball-milling. Various milling parameter were optimized to get required particle sizes. Synthesized nanoparticles were characterized for their structure and particle sizes using $\mathrm{X}$-ray diffraction (XRD), scanning electron microscopy (SEM), transmission electron microscopy (TEM) and dynamic light scattering (DLS) techniques. The UV-Visible transmission shows the blue shift in cutoff, which indicate nearly stoichiometric composition of the prepared material. It has been observed that the sizes of particles decreases with increasing milling speed and time. Observed particle sizes were found in the range $\sim 30-60 \mathrm{~nm}$.
\end{abstract}

Keywords Nanoparticles; Ball-milling; Lithium niobate; XRD; TEM; Transmission

\section{Introduction}

Lithium niobate, $\mathrm{LiNbO}_{3}$ crystal is one of the most versatile synthetic materials. It is negative uniaxial, highly birefringent and has remarkable combination of piezoelectric and optical properties. These properties makes $\mathrm{LiNbO}_{3}$, a technologically important material, particularly as a non-linear optical, electro-optical, and related interdisciplinary fields [1-3]. In the past decade, significant interest has been focused on the synthesis of nanoscale materials due to their interesting properties emerging from the dimensional confinement, and has great potential for device applications. Nanocrystalline particles either pure or embedded into a suitable host material show new physical effects $[4,5]$. As size reduces into nanometer range, the material exhibit interesting mechanical and physical properties, e.g. increased mechanical strength, enhanced diffusivity, higher specific heat and electrical resistivity compared to conventional coarse grained counterparts. The unique features of nano-sized piezo ferroelectrics, pyro ferroelectrics, and ferroelectrics enable a broad spectrum of thermo-electrical, electro-mechanical, electronic, and dielectric properties for sensors and actuators, compact electronics, pyro sensors, and thermal imaging $[6,7]$. Piezoelectric nanowires have been studied as potential strain-based energy harvesting devices e.g. direct current generators [8-10]. The rapid progress in synthesis of ferroelectrics nanoparticles, in particular vertical arrays of free-standing tubes, wires and rods in porous template demonstrated their enhanced polar properties and unusual domain structure [11-14]. It has been reported that the pyroelectric coefficient increases strongly as the wire radius decreases and diverges at critical radius $\mathrm{R}_{\mathrm{cr}}$ corresponding to size driven transition into paraelectric phase [15]. Size driven enhancement in pyroelectric coupling leads to giant pyroelectric current and voltage generation by polarized ferroelectric nanoparticles in response to the temperature fluctuation. The size effect can be used to tune the phase transition temperature in ferroelectric nanostructure, thus enabling the system with tunable giant pyroelectric response.

Many synthesis routes are being developed for $\mathrm{LiNbO}_{3}$ at the nanoscale resulting in different size, shape, and crystalline quality. $\mathrm{LiNbO}_{3}$ nanoparticles have been previously produced by milling [16] non-aqueous route [17] sol-gel method [18] or hydrothermal route [19]. Polycrystalline $\mathrm{LiNbO}_{3}$ nanotubes have also been reported [20] as well as a solution-phase synthesis to produce rod like structures among other multiple structures [21]. This enhancement is related to larger drift length of the photo-holes (lifetime) due to trapping of electrons on the nanoparticles and creation of recombination barrier at the polymer/nanoparticle interface at higher nanoparticle concentration.

In this paper we report the preparation of lithium niobate, $\mathrm{LiNbO}_{3}$ nanoparticles by high energy ball milling. The milling parameters were optimized for obtaining the desired phase and particle size. The prepared particles were characterised for phase, crystallinity and sizes using powder $\mathrm{XRD}$, SEM, TEM and dynamic light scattering (DLS) 
techniques. UV-Visible transmission was also recorded to investigate the stoichiometry of the prepared particles. The results on nano-scale material were compared with their bulk counterpart.

\section{Experimental Details}

$\mathrm{LiNbO}_{3}$ powder was synthesized by solid-state reaction method using lithium carbonate $\left(\mathrm{Li}_{2} \mathrm{CO}_{3}, 99.99 \%\right)$ and niobium pentaoxide $\left(\mathrm{Nb}_{2} \mathrm{O}_{5}, 99.99 \%\right)$ as starting materials in stoichiometric composition. After proper mixing the starting powders, it was placed in platinum crucible inside a resistive heating furnace and calcined at $950{ }^{\circ} \mathrm{C}$ for $24 \mathrm{~h}$. This stoichiometric $\mathrm{LiNbO}_{3}$ powder was used for preparing the nanoparticles by planetary high energy ball mill. The planetary micro mill, Pulverisette 7 premium line (Fritsch $\mathrm{GmbH}$ ) was used for milling. It is useful for both dry and wet grinding of inorganic and organic samples. It has two containers made of zirconia oxide whose density is $5.7 \mathrm{~g} / \mathrm{cm}^{3}$, hardness is 8.1 Mohs and is resist to acids except for hydrofluoric acid. The volume of the container is about 80 $\mathrm{ml}$. Zirconia balls with diameters of $2 \mathrm{~mm}$ and $5 \mathrm{~mm}$ were used for milling purpose. We used the wet grinding process for preparing $\mathrm{LiNbO}_{3}$ (LN) nanoparticles. Stoichiometric $\mathrm{LiNbO}_{3}$ powder prepared as above was put into two containers ( $10 \mathrm{~g}$ each). For wet grinding, $12 \mathrm{ml}$ of $\mathrm{n}$-heptane or ethanol was used in each container as a grinding medium. Oleic acid, $2 \mathrm{ml}$ in each container was used as surfactant to prevent agglomeration of nanoparticles. We have optimized the ball to powder mass ratio (BPMR), which is very important parameter to achieve the desired particle sizes. We have taken 2:1 BPMR, for $10 \mathrm{~g}$ of $\mathrm{LiNbO}_{3}$ powder, we used $20 \mathrm{~g}$ of zirconia balls and put into both the containers. Milling was done for different milling time and speed (rpm). Several run were performed to get nano-size particles. As the speed of machine is very high during rotation, temperature of the bowl may increase abruptly. To avoid this, pause time is required in between two rotation cycle. Pause time was set as $5 \mathrm{~min}$ for every cycle. Speed (rpm) of machine, total time of milling, milling media and other milling parameters were optimized by performing set of experiments. Milling parameters are given in Table 1.

The synthesized nanoparticles were examined by powder X-ray diffraction using $\mathrm{Cu} \mathrm{K}_{\alpha}$ radiation $(\lambda=1.5406 \AA$, Rigaku Geiger Flex X-ray diffractometer) in the range of

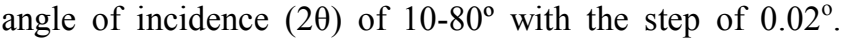
These LN nanoparticles were suspended in de-ionized water homogeneously by several stirring followed by ultrasonication and the particle size distribution was determined by dynamic light scattering, DLS (Zetasizer Nano ZS90; ZEN-3690). The surface morphology and textural properties of the prepared powders were investigated using JEOL JSM-5600 scanning electron microscope (SEM). The crystallinity, microstructure and particle sizes were also examined using TEM (Philips, Tecnai G ${ }^{2}-20$ (FEI)). Sample for TEM observation was prepared by suspending the particles in ethanol by ultrasonification and drying a drop of the suspension on a carbon coated copper grid. UV-Vis transmission was recorded using UV-Vis spectrophotometer (cary-50) to investigate the lower cutoff of the transmission which is indirect measure of the stoichiometry of the material.

Table 1. Milling parameters for lithium niobate preparation

\begin{tabular}{|c|c|c|c|c|c|c|}
\hline S. No. & $\begin{array}{l}\text { Speed } \\
\text { (rpm) }\end{array}$ & $\begin{array}{c}\text { Weight } \\
\text { (gm) }\end{array}$ & $\begin{array}{c}\text { Total } \\
\text { time (h) }\end{array}$ & BPMR & $\begin{array}{l}\text { Milling media } \\
\& \text { surfactant }\end{array}$ & $\begin{array}{l}\text { Pause } \\
\text { time }\end{array}$ \\
\hline 1 & 500 & 10 & 5 & $1: 1$ & $\begin{array}{c}\text { n-heptane \& } \\
\text { oleic acid }\end{array}$ & $5 \mathrm{~min}$ \\
\hline 2 & 500 & 10 & 8 & $2: 1$ & $\begin{array}{l}\text { Ethanol \& } \\
\text { oleic acid }\end{array}$ & $5 \mathrm{~min}$ \\
\hline 3 & 700 & 10 & 5 & $2: 1$ & $\begin{array}{r}\text { Ethanol \& } \\
\text { oleic acid }\end{array}$ & $5 \mathrm{~min}$ \\
\hline 4 & 700 & 10 & 8 & $2: 1$ & $\begin{array}{r}\text { Ethanol \& } \\
\text { oleic acid }\end{array}$ & $5 \mathrm{~min}$ \\
\hline 5 & 700 & 10 & 10 & $2: 1$ & $\begin{array}{l}\text { Ethanol \& } \\
\text { oleic acid }\end{array}$ & $5 \mathrm{~min}$ \\
\hline
\end{tabular}




\section{Results and Discussion}

The preparation of $\mathrm{LiNbO}_{3}(\mathrm{LN})$ has been taken up in view of the fact that the nano size particles could be source material for bio-imaging using its second harmonic generation (SHG) properties [22]. The hydrothermal grown freestanding $\mathrm{LiNbO}_{3}$ nanowire show efficient nanoscale second harmonic generation (SHG) light source [23]. As has been reported earlier the nanocrystalline particles of sufficiently lower sizes embedded into a suitable host matrix i.e. adding particles to liquids leads to modified optical or mechanical properties [24, 25]. Therefore the oxide nanoparticles in a specific sizes are promising for photonics applications [26, 27]. Mansurvo et al. studied the photoconductive properties of a hybrid material based on poly N-vinylcarbazole (PVK) doped with $\mathrm{LiNbO}_{3}$ nanoparticles and found that the photo conductivity of the composite increases remarkably with the nanoparticle content [28]. In view of these specific advantages in the nano size regime, the nanoparticles of $\mathrm{LiNbO}_{3}(\mathrm{LN})$ were prepared by wet grinding process in a planetary ball mill. These pasrticles were investigated for their phase, crystallinity, microstructure and particle sizes. The crystalline phase was determined by powder X-ray diffraction (XRD). Fig.1(a) shows the representative powder XRD pattern for LN particles ball-milled at $700 \mathrm{rpm}$ for $8 \mathrm{~h}$. For comparison the XRD pattern for bulk single crystal is given in Fig. 1(b). It can be seen from the XRD patterns that the prepared phase is matching well with the Miller indices corresponding to the pure hexagonal phase of bulk crystalline $\mathrm{LiNbO}_{3}$ structure (JCPDS no. 20-0631). The average particle size was calculated from (012) diffraction peak using Scherer's

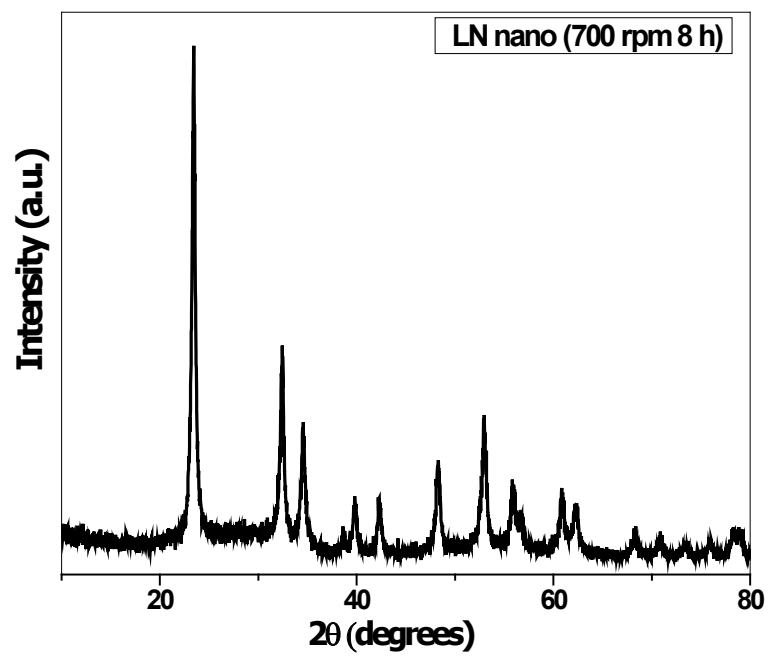

equation: $D=0.9 \lambda /(\beta \cos \theta)$, where $D$ is average crystallite size in $\mathrm{mm}, \lambda$ is the wavelength of $\mathrm{X}$-ray source $(0.15418$ $\mathrm{nm}$ ), $\beta$ (in radian) is full width at half maximum of the peak. The average particle size calculated were approximately 30 $\mathrm{nm}, 25 \mathrm{~nm}$, and $21 \mathrm{~nm}$ for the samples milled at $700 \mathrm{rpm}$, for 5,8 , and 10 respectively. From the above XRD results it has been observed that broadening of the diffraction peaks increases and the peak intensity of the peak is decreases with increasing milling time and $\mathrm{rpm}$. This indicates that the particle size decreases with increasing milling time and rpm.

Laser diffraction is widely used technique for measuring the size of particles. The particle size of suspensions and emulsions are commonly analyzed by light scattering techniques; either static (laser diffraction) or dynamic (Brownian movement). If particle size is less than wavelength of incident light then dynamic scattering is used otherwise static scattering is preferable. The synthesized LN nanoparticles were examined by Zetasizer nanoseries. LN nanoparticles were suspended in de-ionized water and after ultrasonication placed into the cuvettes for measurement of particle size distribution. The representative particle size distribution for the $\mathrm{LiNbO}_{3}$ nanoparticles ball milled at 500 $\mathrm{rpm}$ for $5 \mathrm{~h}$ is shown in Fig. 2a. From the figure it is seen that the particle size is $161 \mathrm{~nm}$. Whereas when the milling parameters e.g. rpm and time are increased to $700 \mathrm{rpm}$ and 8 $\mathrm{h}$ the sizes decreased to around $57 \mathrm{~nm}$ for $95 \%$ of the sample. The representative particle size distribution for the $\mathrm{LN}$ samples ball milled at $700 \mathrm{rpm}$ for $8 \mathrm{~h}$ is shown in Fig. $2 \mathrm{~b}$. The DLS measurements on the samples ball milled for longer durations shows the reduction in particle sizes. Similar results were found in the XRD data as well.

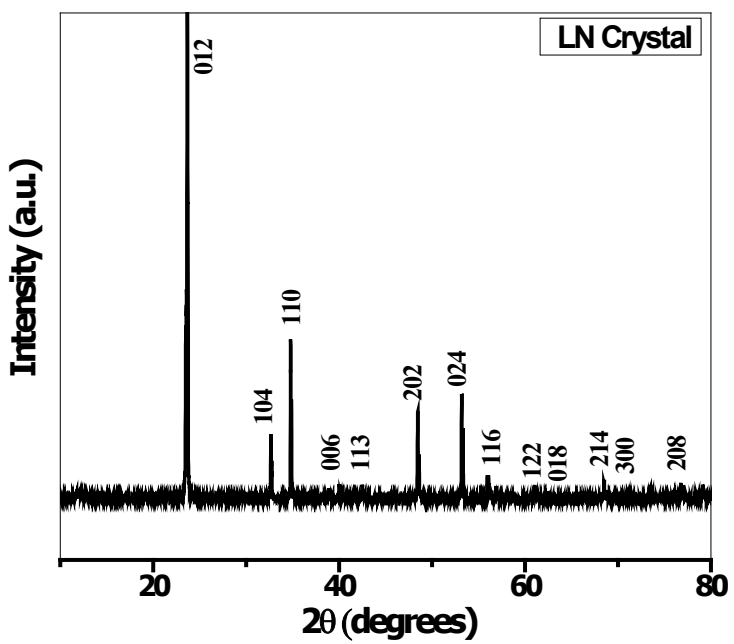

Figure 1. (a) XRD of LN nanocrystal ball-milled at $700 \mathrm{rpm}$ for $8 \mathrm{~h}$, (b) XRD pattern for bulk LN crystal for comparison 

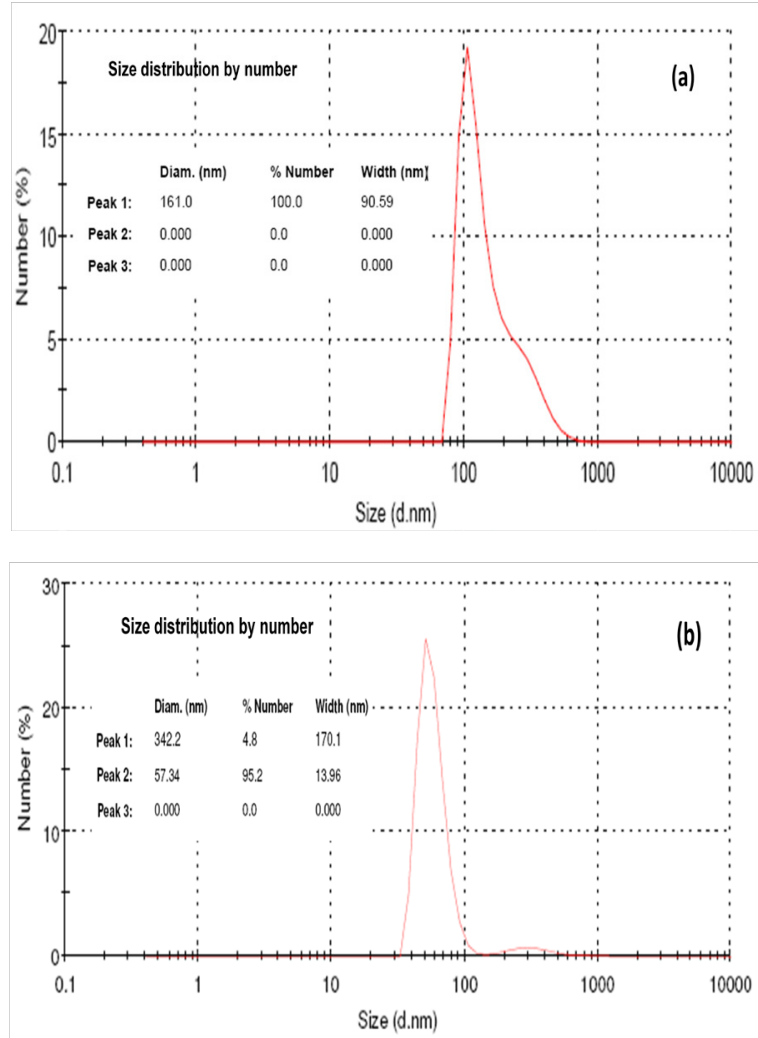

Figure 2. Particle size graph of $\mathrm{LiNbO}_{3}$ nanocrystals ball milled at (a) 500 rpm for $5 \mathrm{~h}$ and (b) $700 \mathrm{rpm}$ for $8 \mathrm{~h}$

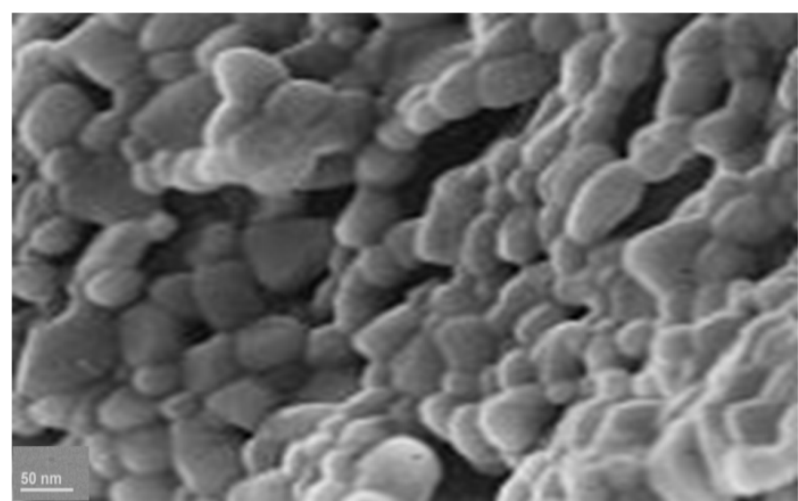

Figure 3. SEM images of $\mathrm{LiNbO}_{3}$ nanocrystals ball milled at $700 \mathrm{rpm}$ for $8 \mathrm{~h}$

The morphology and textural properties of the prepared powders were investigated by scanning electron microscopy (SEM). Fig. 3 shows the representative SEM micrograph taken for $\mathrm{LiNbO}_{3}$ nanoparticles ball milled at $700 \mathrm{rpm}$ for $8 \mathrm{~h}$. These SEM images exhibits highly agglomerated particles having some voids. Images also show that the particles are irregular in shape, with a variation in morphology and the sizes. Transmission electronic microscopy (TEM) in diffraction, normal image and high-resolution mode is best tool to analyze the phase, morphology, microstructure and the sizes of the nanoparticles [29-31]. Fig. 4 (a) shows the representative TEM micrographs taken for the samples of $\mathrm{LiNbO}_{3}$ nanoparticles ball milled at $500 \mathrm{rpm}$ for $5 \mathrm{~h}$ in normal image mode. Fig. 4 (b, c) shows the representative
TEM micrographs taken for the samples of $\mathrm{LiNbO}_{3}$ nanoparticles ball milled at $700 \mathrm{rpm}$ for $8 \mathrm{~h}$ in normal image and high-resolution mode. The corresponding selected area diffraction (SAED) patterns are inserted into the micrograph. The TEM micrograph shown in Fig. 4 (a) reveals the formation of nanoparticles with varying sizes. The particle sizes are mostly $>100 \mathrm{~nm}$ size. The same were observed in DLS results for the samples milled at lower rpm for less time. Whereas the TEM micrograph shown in Fig. 4 (b) shows the particle sizes are mostly in $\sim 30-60 \mathrm{~nm}$ range, and very few are above $100 \mathrm{~nm}$. These sizes of the particles are sufficient to diffract and produce SAED pattern. The SAED diffraction pattern inserted into the micrograph (Fig 4 $(a, b))$ shows the basal plan, as beam direction is [10.0] zone axis. The sharpness of the spots suggest formation of pure $\mathrm{LN}$ phase, there is no secondary phase in the sample. The lattice parameters calculated from SAED patterns and also from the XRD patterns matches well with the hexagonal phase of stoichiometric $\mathrm{LiNbO}_{3}$.
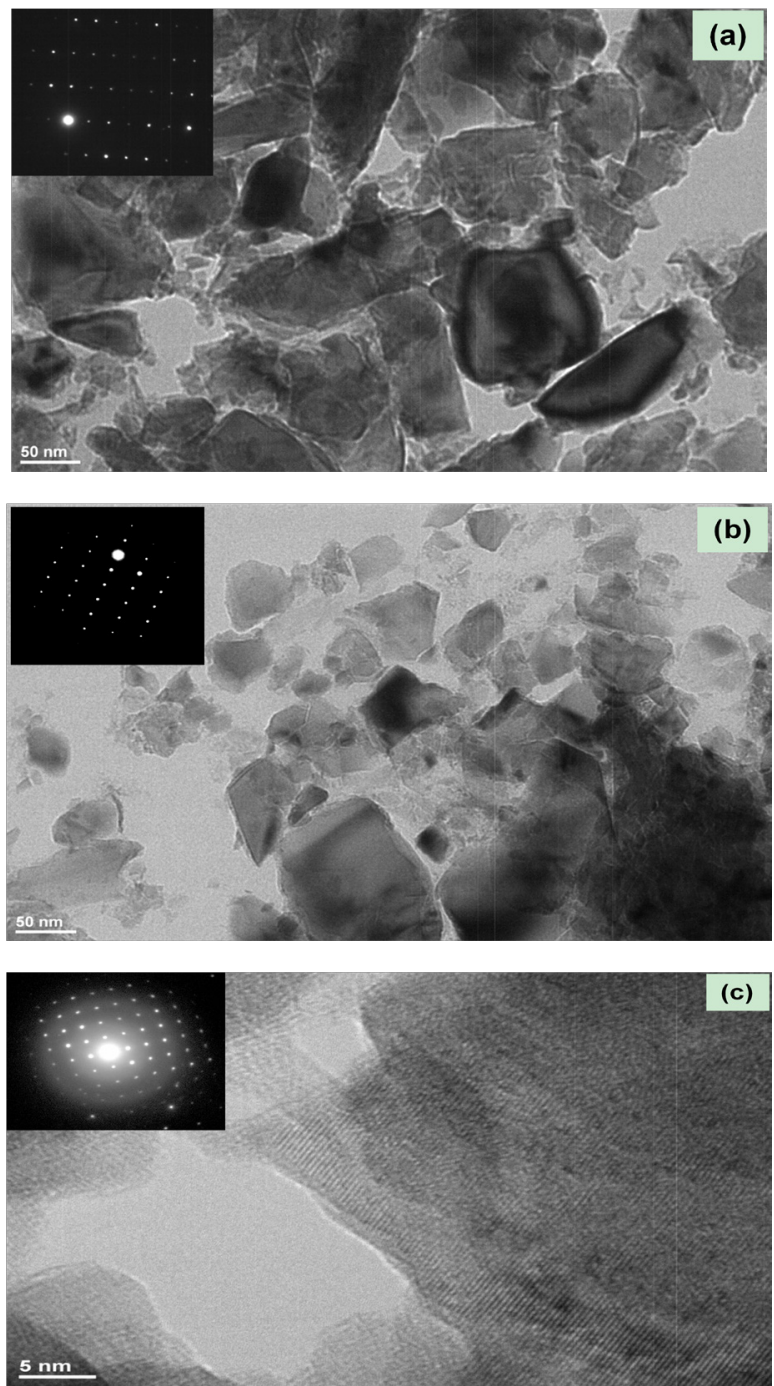

Figure 4. TEM images of $\mathrm{LiNbO}_{3}$ nanocrystals ball milled at (a) $500 \mathrm{rpm}$ for $5 \mathrm{~h}$, (b) $700 \mathrm{rpm}$ for $8 \mathrm{~h}$ in normal image and (c) $700 \mathrm{rpm}$ for $8 \mathrm{~h}$ in high resolution mode. The corresponding SEAD patterns are inserted into the micrographs 
The high-resolution electron micrograph (HRTEM) for the same sample shown in Fig. 4 (c). The clear lattice fringes in the HRTEM micrograph shows that the highly ordered and defect free single phase particles are formed. The lattice fringes further suggests that there are negligible crystalline defects at microstructure level. This is further supported by the SAED pattern inserted into the HRTEM micrograph in Fig. 4 (c). The clean square SAED pattern in Fig. 4 (c) shows the basal plan, when the beam direction is [11.0] zone axis. The above TEM results in diffraction and high-resolution image mode suggest the successful preparation of LN nanoparticles with the particle sizes ranging $\sim 30-60 \mathrm{~nm}$. The investigations also reveal that the initial pure hexagonal phase of $\mathrm{LiNbO}_{3}$ remains after high energy ball-milling. The particle size of the as prepared materials was found to decrease with increasing milling speed and time. The distribution of particle sizes are quite similar in SEM, TEM and DLS results. However, as expected the XRD results show little smaller sizes since XRD results are drawn from the FWHM which arises due to several other factors like scattering, stress, instrumental broadening etc.

Ultraviolet-visible spectroscopy of $\mathrm{LiNbO}_{3}$ shows absorption in the UV-visible spectral region. Ultraviolet and visible spectroscopy is a reliable and accurate analytical procedure for the analysis of a substance. Specifically, ultraviolet and visible spectroscopy measures the absorption, transmission and emission of ultraviolet and visible light wavelengths by matter. It is also used to measure UV cutoff shift in transmission and absorption graph of a given material. The ball milled nanoparticles were examined by UV-Visible spectrophotometer. For measuring the transmittance, thin film of $\mathrm{LiNbO}_{3}$ nanoparticles was prepared by spin coating method. To prepare thin film, a polymer, tri-methyl ammonium bromide $\left(\mathrm{C}_{19} \mathrm{H}_{4} 2 \mathrm{BrN}\right)$ was used. It has very good adhesive property, which is necessary parameter for making films on a certain substrate. The solution of $20 \mathrm{ml}$ polymer in water was made and $50 \mathrm{mg} \mathrm{LN}$ nanoparticles were mixed into it. This solution was stirred well and one drop of this solution was put on the glass slide. This slide was put on the rotor of the spin coating machine. The slide was rotated at $1100 \mathrm{rpm}$. Thin film of the nanoparticles spread over the slide and was used for the transmission measurements.

Fig. 5(a, b) shows the transmission spectrum for nanoparticles and bulk lithium niobate (LN) crystal. From the figure it can be seen that the UV cutoff for bulk crystal is at $312 \mathrm{~nm}$ (Fig. $5 \mathrm{~b}$ ). It is well known that LN crystals always grow with Li deficiency (48.6 mol\% of Li). Due to this $\mathrm{Li}$ deficiency the UV cutoff is red shifted. However, for stoichiometric LN the UV cutoff is $280 \mathrm{~nm}$. Fig. 5(a) shows that the UV cutoff for LN nanoparticles reduces to $288 \mathrm{~nm}$. The blue shift in UV cutoff from $312 \mathrm{~nm}$ to $288 \mathrm{~nm}$ suggests that the composition of prepared LN in nearly stoichiometric. It has been reported that the $\mathrm{LN}$ nanoparticles prepared by modified sol-gel technique retains the near stoichiometric composition [32]. This implies that the band gap increases for lithium niobate nanoparticles. This increase in band gap occurs due to quantum confinement effect. The transmission of the nanoparticle thin film was found $\sim 80 \%$, which is higher than that of the bulk crystals $(\sim 70 \%)$. The above results are indicative of the fact that the $\mathrm{LN}$ nanoparticles dispersed in a suitable matrix have very good potential for the non-linear optical (NLO) device applications. These LN nanoparticles have potential to be exploited as bio-imaging materials using their SHG characteristics. Also there is possibility of using their photovoltaic properties to kill virus with the produced current.
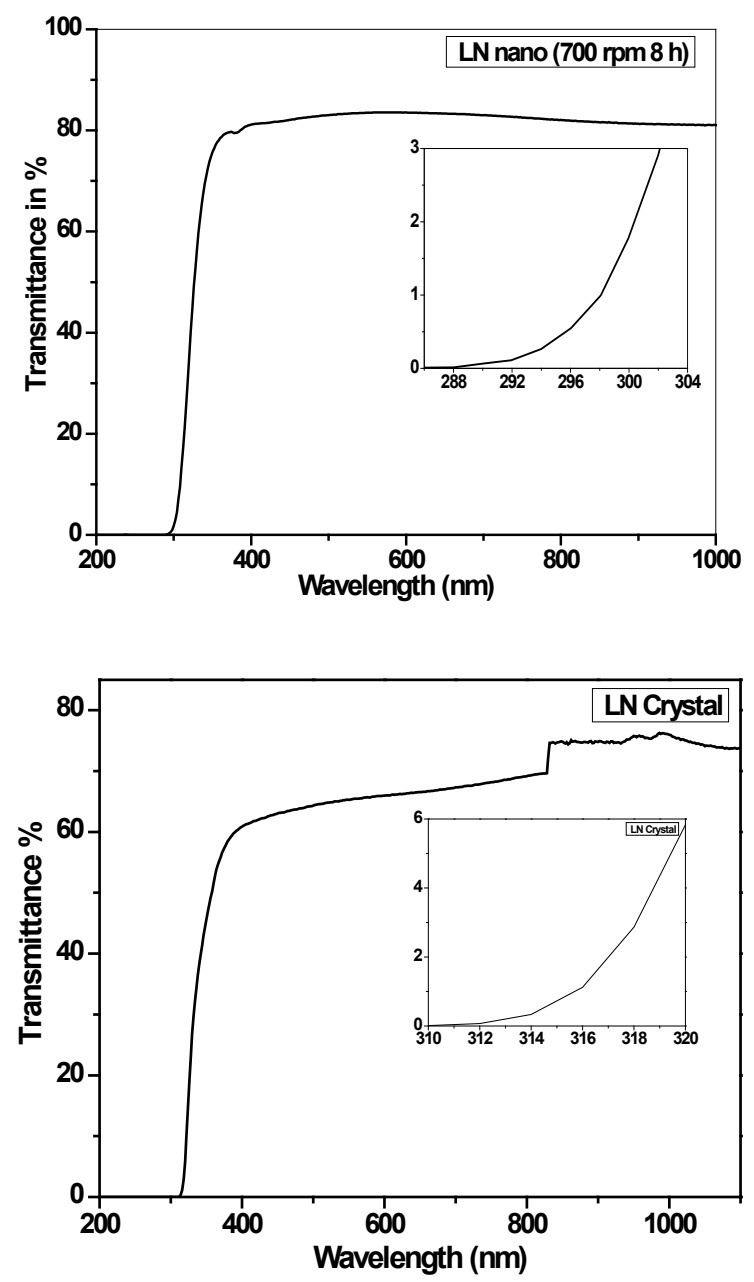

Figure 5. Transmission spectra of $\mathrm{LiNbO}_{3}$ nanocrystals (ball milled at 700 rpm for $8 \mathrm{~h}$ ) and bulk crystal

\section{Conclusions}

$\mathrm{LiNbO}_{3}$ nanoparticles were prepared by high energy ball milling technique. Different parameters like ball to powder mass ratio, rpm, milling time, ball size etc. were optimized to get almost uniform particle size. It has been observed that wet grinding is preferred to get smaller particle size. The prepared nanoparticles were characterized for their phase, structure, particle size and stoichiometry. XRD results show that the prepared particles retain the phase and the crystal structure of the initial $\mathrm{LiNbO}_{3}$ powder. TEM results in diffraction and high-resolution image mode suggest the 
successful preparation of the LN nanoparticles. The particle sizes using different techniques of XRD, DLS, SEM and TEM were found ranging $\sim 30-60 \mathrm{~nm}$. It has been observed that particle size decreases with the increase of milling time and rpm. It was observed that the UV cutoff of the nanoparticles of $\mathrm{LiNbO}_{3}$ was shifted towards the lower wavelength (blue-shift). This implies that the band gap increases for nano size lithium niobate.

\section{REFERENCES}

[1] K. Buse, Light-induced charge transport processes in photorefractive crystals, Appl. Phys. B Vol.64, 273-291, 1997.

[2] R.S. Weis, T.K. Gaylord, Lithium niobate: Summary of physical properties and crystal structure, Appl. Phys. A Vol.37, 191-203, 1985.

[3] F. Abdi, M. Aillerie, P. Bourson, M.D. Fontana, Electro-optic properties in pure $\mathrm{LiNbO}_{3}$ crystals from the congruent to the stoichiometric composition, J. Appl. Phys. Vol.84, 2251-2254, 1998.

[4] S.C. Tjong H. Chen, Nanocrystalline materials and coatings, Mat. Sci. \& Engg. R, Vol.45, 1-88, 2004.

[5] H. Gleiter, Nanocrystalline materials, Prog. Mater. Sci. Vol.33, 223-315, 1989.

[6] S.B. Lang, Pyroelectricity: from ancient curiosity to modern imaging tool, Physics Today, Vol.58, 31-35, 2005.

[7] J.F. Scott, Data storage: Multiferroic memories, Nature Materials, Vol.6, 256-257, 2007.

[8] Z.L. Wang, J. Song, Piezoelectric nanogenerators based on zinc oxide nanowire arrays, Science, Vol.312, 241-246, 2006.

[9] X. Wang, J. Song, J. Liu, Z.L. Wang, Direct current nanogenerator driven by ultrasonic wave, Science, Vol. 316, 102-105, 2007.

[10] Y. Qin, X. Wang, Z.L. Wang, Microfiber-nanowire hybrid structure for energy scavenging, Nature, Vol. 451, 809-813, 2008.

[11] Y. Luo, I. Szafraniak, N.D. Zakharov, V. Nagarajan, M. Steinhart, R.B. Wehrspohn, J.H. Wendorff, R. Ramesh, M. Alexe, Nanoshell tubes of ferroelectric lead zirconate titanate and barium titanate, Appl. Phys. Lett. Vol. 83, 440-442, 2003.

[12] Z.H. Zhou, X. S. Gao, J. Wang, K. Fujihara, S. Ramakrishna, V. Nagarajan, Giant strain in $\mathrm{PbZr}_{0.2} \mathrm{Ti}_{0.8} \mathrm{O}_{3}$ nanowires, Appl. Phys. Lett. Vol.90, 052902-5, 2007.

[13] D. Yadlovker, S. Berger, Uniform orientation and size of ferroelectric domains, Phys. Rev. B Vol.71, 184112-8, 2005.

[14] D. Yadlovker, S. Berger, Ferroelectric single-crystal nano-rods grown within a nano-porous aluminum oxide matrix, J. Electroceram. Vol.22, 281-284, 2009.

[15] A.N. Morozovska, E.A. Eliseev, G.S. Svechnikov, S.V. Kalinin, Pyroelectric response of ferroelectric nanowires: Size effect and electric energy harvesting, J Appl. Phys.
Vol.108, 042009-14, 2010.

[16] J.R. Schwesyg, H.A. Eggert, K. Buse, E. Sliwinska, S. Khalil, M. Kaiser, K. Meerholz, Fabrication and optical characterization of stable suspensions of iron- or copper-doped lithium niobate nanocrystals in heptane, Appl. Phys. B: Lasers Opt. Vol.89, 15-17, 2007.

[17] M. Niederberger, N. Pinna, J. Polleux, M. Antonietti, A general soft-chemistry route to perovskites and related materials: Synthesis of $\mathrm{BaTiO}_{3}, \mathrm{BaZrO}_{3}$, and $\mathrm{LiNbO}_{3}$ nanoparticles, Angew. Chem.,Int. Ed. Vol.43, 2270-73, 2004.

[18] L.H. Wang, D.R. Yuan, X.L. Duan, X.Q. Wang, F.P. Yu, Synthesis and characterization of fine lithium niobate powders by sol- gel method, Cryst. Res. Technol. Vol.42, 321-324, 2007.

[19] C.H. An, K.B. Tang, C.R. Wang, G.Z. Shen, Y. Jin, Y.T. Qian, Characterization of $\mathrm{LiNbO}_{3}$ nanocrystals prepared via a convenient hydrothermal route, Mater. Res. Bull. Vol.37, 1791-96, 2002.

[20] L.L. Zhao, M. Steinhart, M. Yosef, S.K. Lee, S. Schlecht, Large-scale template-assisted growth of LiNbO3 one-dimensional nanostructures for nanosensors, Sensors \& Actuators B Vol.109, 86-90, 2005.

[21] B.D. Wood, V. Mocanu, B.D. Gates, Solution-Phase Synthesis of Crystalline Lithium Niobate Nanostructures, Adv. Mater. Vol.20, 4552-4556, 2008.

[22] B. Knabe, K. Buse, Spontaneous polarization in ultrasmall lithium niobate nanocrystals revealed by second harmonic generation, Phys. Rev. B vol.86, 195428-9, 2012.

[23] R. Grange, J.W. Choi, C.L. Hsieh, Y. Pu, A. Magrez, R. Smajda, L. Forró, D. Psaltis, Lithium niobate nanowires synthesis, optical properties, and manipulation, Appl. Phys. Letts. Vol.95, 143105-8, 2009.

[24] D. Psaltis, S.R. Quake, C. Yang, Developing optofluidic technology through the fusion of microfluidics and optics, Nature, Vol.442, 381-386, 2006.

[25] J.R. Adleman, H.A. Eggert, K. Buse, D. Psaltis, Holographic grating formation in a colloidal suspension of silver nanoparticles, Opt. Lett. Vol.31, 447-449, 2006.

[26] A. Majchrowski, J. Ebothe, E. Gondek, K. Ozga, I.V. Kityk, A.H. Reshak, T. Łukasiewicz, Photoinduced nonlinear optical effects in the $\mathrm{Pr}$ doped $\mathrm{BiB}_{3} \mathrm{O}_{6}$ glass nanoparticles incorporated into the polymer matrices, J. Alloys \& Compd. Vol.485, 29-32, 2009.

[27] Y. Djaoued, K. Ozga, A. Wojciechowski, A.H. Reshak, J. Robichaud, I.V. Kityk, Photoinduced effects in $\mathrm{TiO}_{2}$ nanocrystalline films with different morphology, J. Alloys \& Compd. Vol.508, 599-605, 2010.

[28] S. Mansurova, K. Meerholz, E. Sliwinska, U. Hartwig, K. Buse, Enhancement of charge carrier transport by doping PVK-based photoconductive polymers with $\mathrm{LiNbO}_{3}$ nanocrystals, Physical Review B Vol.79, 174208-15, 2009.

[29] R. Dwivedi, A. Maurya, A. Verma, R. Prasad, K.S. Bartwal, Microwave assisted sol- gel synthesis of tetragonal zirconia nanoparticles, J. Alloys and Compounds, Vol.509, 6848-51, 2011. 
[30] S. Kar, S. Verma, K.S. Bartwal, Preparation of Mn doped $\mathrm{Li}_{2} \mathrm{~B}_{4} \mathrm{O}_{7}$ nanoparticles by glass quenching, J. Alloys and Compounds, Vol.495, 288-291, 2010.

[31] N. Kaithwas, M. Dave, S. Kar, K.S. Bartwal, Structural features of $\mathrm{Ce}$ doped YAG nanoparticles synthesised by modified sol-gel method, Physica E Vol.44, 1486-89, 2012.
[32] C. Debnath, S. Kar, S. Verma, K.S. Bartwal, Effect of metal ion ratio and $\mathrm{pH}$ on the synthesis of single phase $\mathrm{LiNbO}_{3}$ by citrate gel method, Mat. Chem. \& Phys. (Under Review). 